Copyright (C) 2014 by Academic Publishing House Researcher

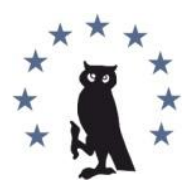

Published in the Russian Federation

European Researcher

Has been issued since 2010.

ISSN 2219-8229

E-ISSN 2224-0136

Vol. 86, No. 11-1, pp. 1957-1963, 2014

DOI: 10.13187/er.2014.86.1957

www.erjournal.ru

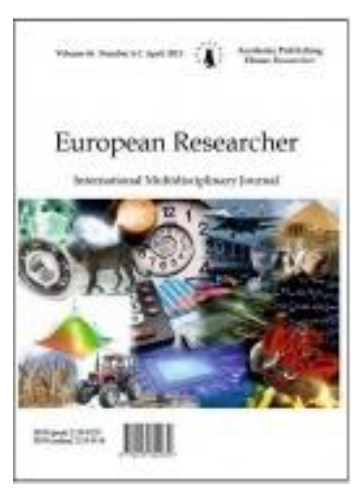

Pedagogical sciences

Педагогические науки

UDC $378: 372.8$

\title{
The Role of Interactive Teaching Methods in Fostering Ethno-Pedagogical Competence in Future Teachers
}

${ }^{1}$ Kymbat F. Aubakirova

${ }^{2}$ Jannur B. Asetova

\begin{abstract}
${ }^{1}$ Karaganda State University of E.A. Buketov, Kazakhstan 100026, Kazakhstan, Karaganda, Universitetskaya Str., 28

$\mathrm{PhD}$

E-mail: kymbat_69@mail.ru

${ }^{2}$ Karaganda State University of E.A. Buketov, Kazakhstan

100026, Kazakhstan, Karaganda, Universitetskaya Str., 28

Master of pedagogical sciences

E-mail: akniet_22@mail.ru
\end{abstract}

\begin{abstract}
The article presents the results of research associated with the study of the role and place of interactive teaching methods in the process of forming ethnopedagogical competence of future teachers. The authors of the article special attention focuses on such methods as: discussion (the discussion on the clash of views, exchange of opinions); "brainstorming" (active search for answers with the help of guesses, ideas, hypotheses, associations); round table (discussing moral issues with representatives of different sectors of society); business game (simulation, emulation, image, reflection, managing different situations and their modeling); contests of practical work with their discussion; training (active correction method by communicating in groups, modeling interpersonal relationships); work in micro-groups; problem solving.

Keywords: competence; ethnopedagogical competence; interactive teaching methods; discussion; brainstorming; round table; business game; training.

\section{Введение} методы.

Особым компонентом формирования этнопедагогической компетентности являются

Поскольку исследуемая нами компетентность, в силу своей содержательнокачественной наполненности, представляет собой динамичную систему, то в процессе ее формирования мы предполагаем активно использовать интерактивные методы, так как они
\end{abstract}


обладают колоссальными возможностями, которые определяются, прежде всего, общением, межличностным взаимодействием, необходимость использования которых диктуется самой природой этих педагогических явлений.

Анализ современного состояния обучения позволяет сделать вывод о том, что вузы в силу недостаточности учебного времени дают в основном теоретические знания, а практически применять их обучающиеся учатся уже в трудовой деятельности, что является парадоксом существующей системы образования.

\section{Материал и методы исследования}

Решению этой и других проблем может способствовать внедрение системы методов активного обучения и воспитания, которая в современных условиях совершенствования процесса подготовки квалифицированных педагогических кадров, активизирует познавательную деятельность обучающихся. Сам процесс учения - это не просто передача научных положений «из головы в голову», это процесс, результат активной познавательной мыслительной деятельности по самостоятельному поиску, и переработке научной информации. В такой учебной деятельности происходит изменение самого действующего субъекта, преобразование опыта.

Использование активных методов обучения позволяет организовать сам процесс обучения как продуктивную творческую деятельность, ориентированную на достижение социальнополезного продукта. Роль интерактивных методов обучения несомненна в том плане, что они позволяют освоить личностно-регулятивные функции познания, что помогает осмыслению самой деятельности педагога, приобщиться к многообразию человеческого познания и его применению в практической деятельности, научиться сотрудничеству, взаимодействию с людьми, активному диалогу и управлению собственным поведением, а также сформировать умения анализировать конкретные методические требования к организации учебных проблемных ситуаций на занятиях (проблемные ситуации: проблемные лекции, самостоятельная работа студентов, эвристическая беседа и пр.).

\section{Обсуждение}

Ведущее место в формировании этнопедагогической компетентности, на наш взгляд, занимают интерактивные методы, которые основаны на активном диалоге, где центральное место занимает не отдельно обучающийся как индивид, а группа взаимодействующих обучающихся, которые, обсуждая вопросы, спорят и соглашаются между собой, стимулируют и активизируют друг друга. И поскольку в основе интерактивных методов заложено общение, то для формирования этнопедагогической компетентности они имеют важное значение. Интерактивные методы развивают интеллектуальную и духовно-нравственную активность, а также коллективное творчество в поисках истины. Они способствуют развитию умений слушать и слышать, отстаивать свою точку зрения и уважать мнение других. Следовательно, интерактивные методы (коммуникативные) - это пути и способы познания человеческих взаимоотношений и взаимодействий, это активный диалог.

«Диалог, - отмечает В.В.Сериков, - это подтверждение для личности ее ценности и, как следствие, рождение желания стать еще лучше. Следовательно, предмет диалога всегда лежит в контексте личностных целей, интересов собеседников... Диалог никогда не сводится к усвоению предмета. Он всегда надпредметен, расширяет границы познавательного за счет обмена не только информацией, но и оценками, гипотезами - откровениями» [1]. Диалогизация процесса обучения способствует активизации деятельности студентов, стимулирует развитие у них познавательного интереса, который повышает познавательную самостоятельность личности, позволяет ей максимально самовыразиться не только в стенах вуза, но и в будущей профессиональной деятельности.

В.В.Сериков выделил несколько условий реализации учебного диалога в средней школе [1]. Опираясь на них, мы выделили условия реализации диалога в высшей школе, которые успешно реализуются, если вопросы для обсуждения подбираются с учетом готовности студентов к диалогу, их открытости для общения, адекватной реакции на неожиданные и неоднозначные суждения; в ходе учебного процесса используются игровые ситуации различного уровня (ролевые, ситуационные, имитационные, театрализованные); проблемное, диалогическое общение представляет собой целостную систему знаний, вопросов, ситуаций, 
способствующих развитию познавательной деятельности студентов; преподаватель систематически диагностирует готовность студентов к диалогу, используя наблюдение, тестирование, контекстные задания, создание преднамеренных ситуаций, тренинги.

Таким образом, диалогизация учебного содержания дает возможность студентам находиться в состоянии постоянного «поиска истины», что позволяет обеспечить личностно-значимый, исследовательский характер процессу обучения в высшей школе.

Среди интерактивных методов: беседа: этическая (диалог, обсуждение норм и правил поведения в обществе) и эвристическая (поиск и нахождение истины); дискуссия (аргументированное столкновение мнений, обмен мнениями); «мозговой штурм» (активный поиск ответов с помощью догадок, идей, гипотез, ассоциаций); круглый стол (обсуждение нравственных проблем с представителями разных слоев общества); деловая игра (имитация, подражание, изображение, отражение, управление разных ситуаций и их моделирование); конкурсы практических работ с их обсуждением; тренинг (активный метод коррекции посредством организации общения в группах, моделирование межличностных взаимоотношений); работа в микрогруппах; решение проблемных ситуаций.

В диалоге продуцируются процессы самопознания, которые имеют несколько уровней протекания: рефлексивное самопознание (чаще всего неорганизованное, спонтанное), познание себя «от другого» и научно-организованный процесс самопознания с помощью специальных методов. Такими методами могут быть тренинги, которые используются при подготовке студентов к будущей профессиональной педагогической деятельности и являются наиболее продуктивными и результативными при формировании этнопедагогической компетентности, так как они имеют общее собирательное значение. В тренингах обычно широко используются различные методы и техники активного обучения: деловые, ролевые и имитационные игры, разбор конкретных ситуаций и групповые дискуссии.

Под тренингами понимают такое обучение, в котором основное внимание уделяется практической отработке изучаемого материала, когда в процессе решения специально заданных задач обучающиеся имеют возможность развить и закрепить необходимые знания и навыки, изменить свое отношение к собственному опыту и применяемым в работе подходам. И здесь диалог приобретает особо значимый характер при условии эмоциональной окрашенности, при его влиянии на оценки, мнения, опоре на личностные смыслы обучаемого, так как ни одна ситуация не актуализируется, не расширяется спектр суждений будущих учителей, если нет подкрепления-идентификации («На его месте я поступил (а) по-другому») и аналогии («Со мной произошел подобный случай»). При решении педагогических задач наблюдается двойная эмоциональная наполненность: с одной стороны, через характер коммуникации участников диалога, с другой - через анализируемые в моделируемой ситуации отношения. Иными словами, тренинги направлены на развитие у обучающихся не только эффективных навыков межличностного взаимодействия, но и на повышение общего уровня их компетентности.

Метод дискуссии, суть которого заключается в проведении учебных групповых дискуссий по конкретной проблеме в относительно небольших группах обучающихся (от 6 до 15 человек), не менее эффективный в формировании исследуемого феномена.

Учебная дискуссия отличается от других видов дискуссий тем, что новизна ее проблематики относится лишь к группе лиц, участвующих в дискуссии, т. е. то решение проблемы, которое уже найдено в науке, предстоит найти в учебном процессе в данной аудитории.

Для преподавателя, организующего дискуссию, результат, как правило, уже заранее известен. Целью здесь является процесс поиска, который должен привести к объективно известному, но субъективно, с точки зрения обучающихся, новому знанию. Это может быть, на наш взгляд, только в том случае, если поиск решения проблемы (групповая дискуссия) полностью управляем со стороны самого преподавателя.

Управление здесь носит двоякий характер. Во-первых, для проведения дискуссии преподаватель создает и поддерживает определенный уровень взаимоотношений обучающихся - отношения доброжелательности и откровенности, т. е. управление дискуссией со стороны преподавателя носит коммуникативный характер. Во-вторых, преподаватель управляет процессом поиска истины. Общепринято, что учебная дискуссия 
допустима и результативна при условии, если преподаватель профессионально компетентен и сумеет обеспечить правильность выводов.

Этот метод, на наш взгляд, позволяет наиболее полно использовать опыт студентов, способствуя лучшему усвоению изучаемого ими материала. Это обусловлено тем, что в групповой дискуссии не преподаватель говорит слушателям о том, что является правильным, а сами обучающиеся вырабатывают доказательства, опираясь на принципы и подходы, предложенные преподавателем, максимально используя свой личный опыт.

Метод решения проблемных ситуаций предполагает переход от накопления знаний к деятельностному, практико-ориентированному подходу. Это один из самых испытанных в практике методов обучения навыкам принятия решений и решения проблем в процессе обучения.

Цель этого метода - научить студентов анализировать информацию, выявлять ключевые проблемы, выбирать альтернативные пути решения, оценивать их, находить оптимальный вариант и формулировать программы действий.

При анализе конкретных ситуаций особенно важно то, что здесь сочетается индивидуальная работа с проблемной ситуацией и групповое обсуждение предложений, подготовленных каждым членом группы. Это позволяет обучающимся развивать навыки групповой, командной работы, что расширяет возможности для решения типичных проблем в рамках изучаемой тематики. В результате проведения обсуждения в группе, определения проблем, нахождения альтернатив, выбора действий и плана их выполнения у обучающихся развиваются навыки анализа и планирования.

Разработка практических ситуаций может происходить двумя путями: на основе описания реальных событий и действий или на базе искусственно сконструированных ситуаций.

Исследователями в этой области разработаны рекомендации по работе с конкретной проблемной ситуацией. Наиболее важными из них при решении этнопедагогических задач являются следующие:

- проблемная ситуация, как правило, не бывает ограничена одной темой или дисциплиной курса, поэтому необходимо использовать межпредметные связи;

- в ходе анализа проблемной ситуации следует выявлять внутренние причины, а не их внешние проявления;

• решение проблемной ситуации должна предполагать выявление неопределенности и неоднозначности;

- анализ и предложенные рекомендации по решению проблемы должны подкрепляться примерами из личного опыта.

Необходимо отметить значимость этого метода для формирования этнопедагогической компетентности будущих учителей, включающей специальную, методическую и коммуникативную компетентности обучающихся в установлении межпредметных связей; аналитическом и системном мышлении; оценке альтернатив; презентации результатов проведенного анализа; оценке последствий, связанных с принятием решений; освоении коммуникативных навыков и навыков работы в команде.

В процессе формирования этнопедагогической компетентности метод «деловые игры» выполняет интегративную роль, поскольку является высшим уровнем творческой деятельности студентов. В процессе подготовки и проведения деловой игры студенты ярко проявляют свои индивидуальные профессиональные и личностные качества, умения нестандартно и оригинально использовать их в практической педагогической деятельности.

Деловые игры характеризуются направленностью на снятие определенных практических проблем, приобретение навыков выполнения конкретных приемов деятельности. Необходимость в играх такого типа возникает тогда, когда имеющихся способностей участников учебной деятельности недостаточно для реализации готовых деятельностных норм, либо происходит рассогласование в деятельности в результате изменения внешних условий, поэтому возникает потребность в развитии недостающих способностей в процессе деловой игры. Деловые игры проходят, как правило, в форме согласованного группового мыслительного поиска, что требует вовлечения в коммуникацию 
всех участников игры. По своей сути этот метод обучения является особой формой коммуникации.

В любом типе коммуникации один из участников является автором, который выражает свою точку зрения. Второй участник является реципиентом, который, воспринимая авторский текст, строит образ того, что понял, чтобы реконструировать авторскую точку зрения. Третий участник коммуникации в рамках деловой игры может быть критиком, который, опираясь на результаты принятого решения, вырабатывает свою собственную точку зрения, более оформленную и совершенную. Четвертый участник - организатор коммуникации - согласует все виды работ и превращает разрозненные усилия в целенаправленное движение по совершенствованию авторской точки зрения.

Завершается деловая игра подведением итогов, где основное внимание направлено на анализ ее результатов, наиболее значимых для практики. Однако завершающая фаза может быть расширена до рефлексии всего хода игры. Объектами такой рефлексии могут стать: динамика индивидуальных, групповых, межгрупповых траекторий движения мыслительных процессов; динамика образования коллективного мнения на основе изменений в межличностных отношениях; позиционность игроков и межпозиционные отношения и т. д.

Таким образом, анализ функций деловых игр в обучении приводит нас к следующему выводу. Именно деловая игра обладает возможностью моделирования и воспроизведения деятельностно-ориентированных отношений, кооперативных коммуникативных связей с вовлечением представителей различных подсистем организации, особо необходимых для формирования этнопедагогической компетентности будущих учителей, педагогическая деятельность которых реализуется в условиях полиэтнической образовательной среды, требующей развития у студентов в процессе обучения не только организационных, методических, но и игротехнических способностей.

В процессе формирования этнопедагогической компетентности будущих учителей необходимо использовать и другие виды дидактических игр с целью совершенствования педагогических знаний и умений. Например, имитационная игра позволяет отработать со студентами разнообразные приемы педагогической техники и профессиональной деятельности: имитацию поведения и действия учителя в отдельных педагогических ситуациях, а в процессе ролевой игры предполагается «проигрывание» студентами определенных ролей в процессе решения конкретной педагогической задачи.

\section{Результаты}

Формы и средства формирования этнопедагогической компетентности будущих учителей (аудиторные, внеаудиторные: клубы, кружки, кураторские часы и т.д., педагогическая практика), традиционны, поэтому мы не будем подробно останавливаться на их описании.

\section{Заключение}

Таким образом, мы представили результаты научного исследования, связанные с изучением роли и места интерактивных методов обучения в процессе формирования этнопедагогической компетентности будущих учителей

\section{Примечания:}

1. Болотов В.А., Сериков В.В. Компетентностная модель: от идеи к образовательной программе // Педагогика. 2003. №10. с. 12.

2. Петровский А.В. Основы педагогики и психологии высшей школы : Учебное пособие для вузов. М.: Рос. гос. гуманит. ун-т, 1994. 448 с.

3. Ильин В.С. Формирование личности школьниук. (целостный1 процесс). М.: Педагогика, 1984. 201 с.

4. Скаткин М.Н. Методология и методика педагогических исследований: в помощь начинающему исследователю. М., 1986. 152 с.

5. Хмель Н.Д. Педагогический процесс в общеобразовательной школе. Алма-Ата, 1990. $60 \mathrm{c}$. 
6. Вербицкий А.А. Активное обучение в высшей школе: контекстный подход: Метод. пособ. М.: Высшая школа,1991. 207 с. $360 \mathrm{c}$.

7. Леднев В.С. Содержание образования: Учебное пособие. М.: Высш. школа, 1989.

8. Мухтарова Ш.М. Формирование национального самосознания студентов в учебновоспитательном процессе ВУЗа. Автореф. дис... канд. пед. наук. Караганда, 2002. 29 с.

9. Шиянов И.Ф., Котова И.Б. Развитие личности в обучении. М., 1999.

10. Гальперин П.Я. Психология мышления и учение о поэтапном формировании умственных действий // Исследование мышления в советской психологии. М.: Наука, 1966. C. 236-277.

11. Кузьмина Н.В. Методы системного педагогического исследования. Л., 1982. 311 с.

12. Зимняя И.А. Ключевые компетентности как результативно-целевая основа компетентностного подхода в образовании. Авторская версия / И.Л. Зимняя. М.: Исследовательский центр проблем качества подготовки специалистов, 2004. 42 с.

\title{
References:
}

1. Bolotov V.A., Serikov V.V. Kompetentnostnaja model': ot idei k obrazovatel'noj programme // Pedagogika.2003 №10 s.12.

2. Petrovskij A.V. Osnovy pedagogiki i psihologii vysshej shkoly : Uchebnoe posobie dlja vuzov. M.: Ros.Gos.gumanit.un-t, 1994. 448 s. $201 \mathrm{~s}$.

3. Il'in V.S. Formirovanie lichnosti shkol'niuk. (celostnyj1 process). M., Pedagogika, 1984.

4. Skatkin M.N. Metodologija i metodika pedagogicheskih issledovanij: v pomoshh' nachinajushhemu issledovatelju. M., 1986. $152 \mathrm{~s}$.

5. Hmel' N.D. Pedagogicheskij process v obshheobrazovatel'noj shkole. Alma-Ata, 1990. 60 s.

6. Verbickij A.A. Aktivnoe obuchenie v vysshej shkole: kontekstnyj podhod: Metod. posob. M.: Vysshaja shkola,1991. $207 \mathrm{~s}$.

7. Lednev V.S. Soderzhanie obrazovanija: Uchebnoe posobie. M.: Vyssh. shkola, 1989. 360 s.

8. Muhtarova Sh.M. Formirovanie nacional'nogo samosoznanija studentov v uchebnovospitatel'nom processe VUZa. Avtoref. dis... kand. ped. nauk. Karaganda, 2002. $29 \mathrm{s.}$

9. Shijanov I.F., Kotova I.B. Razvitie lichnosti v obuchenii. M., 1999.

10. Gal'perin P.Ja. Psihologija myshlenija i uchenie o pojetapnom formirovanii umstvennyh dejstvij // Issledovanie myshlenija v sovetskoj psihologii. M.: Nauka, 1966. S. 236-277.

11. Kuz'mina N.V. Metody sistemnogo pedagogicheskogo issledovanija. L., 1982. $311 \mathrm{s.}$

12. 3imnjaja I.A. Kljuchevye kompetentnosti kak rezul'tativno-celevaja osnova kompetentnostnogo podhoda v obrazovanii. Avtorskaja versija / I.L.Zimnjaja. M.: Issledovatel'skij centr problem kachestva podgotovki specialistov, 2004. $42 \mathrm{~s}$.

УДК $378: 372.8$

\section{Роль интерактивных методов обучения в формировании этнопедагогической компетентности будущих учителей}

\author{
${ }^{1}$ Кымбат Файзуллиновна Аубакирова \\ 2 Жаннур Бахытовна Асетова
}

\author{
1-2 Карагандинский государственный университет им. Е.А. Букетова, Казахстан \\ 100026, Казахстан, г. Караганда, ул. Университетская, 28 \\ Кандидат педагогических наук, доцент \\ E-mail: kymbat_69@mail.ru \\ ${ }_{2}^{2}$ Магистр педагогических наук \\ E-mail: -mail: akniet_22@mail.ru
}

Аннотация. В статье представлены результаты научного исследования, связанные с изучением роли и места интерактивных методов обучения в процессе формирования 
этнопедагогической компетентности будущих учителей. Авторы статьи особое внимание акцентируют на таких методах, как дискуссия (аргументированное столкновение мнений, обмен мнениями); «мозговой штурм» (активный поиск ответов с помощью догадок, идей, гипотез, ассоциаций); круглый стол (обсуждение нравственных проблем с представителями разных слоев общества); деловая игра (имитация, подражание, изображение, отражение, управление разных ситуаций и их моделирование); конкурсы практических работ с их обсуждением; тренинг (активный метод коррекции посредством организации общения в группах, моделирование межличностных взаимоотношений); работа в микрогруппах; решение проблемных ситуаций.

Ключевые слова: компетентность; этнопедагогическая компетентность; интерактивные методы обучения; дискуссия; мозговой штурм; круглый стол; деловая игра; тренинг 